\title{
Advances and Limitations of Evidence-Based Medicine - Impact for Probiotics
}

\author{
Hania Szajewska \\ Department of Pediatrics, The Medical University of Warsaw, Warsaw, Poland
}

\section{Introduction}

Evidence-based medicine recommends performance of randomized controlled trials (RCTs) and systematic reviews (or meta-analyses) of RCTs when addressing questions regarding the effects of therapeutic and prophylactic interventions. They are now a well-established means of reviewing existing evidence and integrating findings from various studies.

\section{What Is a Systematic Review? What Is a Meta-Analysis?}

Although the terms 'systematic reviews' and 'metaanalyses' are commonly used interchangeably, there is a distinction between the two. As defined by the Cochrane Collaboration [1], a systematic review is 'a review of a clearly formulated question that uses systematic and explicit methods to identify, select and critically appraise relevant research, and to collect and analyze data from studies that are included in the review. Statistical methods may or may not be used to analyze and summarize the results of the included trials'. A 'meta-analysis' is a name that is given to any review article when statistical techniques are used in a systematic review to combine the results of included trials to produce a single estimate of the effect of a particular intervention (i.e., a number or a graph) [1]. There are 2 major reasons why a metaanalysis is performed within a systematic review. The first is to increase the power, i.e. the chance to reliably detect a clinically important difference if one actually exists. The problem with many individual studies is that they are too small to detect little effects, which can only be observed if the data from several trials are combined. The second reason is to improve precision in estimating effects, i.e. narrow the confidence interval around the effect [1].

\section{Published Meta-Analyses on the Effects of Probiotics}

A Pubmed search in December 2009 of the words 'meta-analysis' or 'systematic review' and 'probiotics' yielded a substantial number of papers, many of which are Cochrane reviews (table 1). To date, the most extensively studied applications and the best-documented areas of efficacy of probiotics are the treatment of acute infectious diarrhea and the prevention of antibiotic-associated diarrhea (AAD). For the first indication, evidence from several meta-analyses of RCTs has consistently shown a sta-

\section{KARGER}

Fax +4161306 1234

E-Mail karger@karger.ch

www.karger.com
(C) 2010 S. Karger AG, Basel

0250-6807/10/0575-0006\$26.00/0

Accessible online at: www.karger.com/anm
Hania Szajewska, MD

Department of Pediatrics, The Medical University of Warsaw

PL-01-184 Warsaw, Dzialdowska 1 (Poland)

Tel./Fax +48 22452 3309, E-Mail hania@ipgate.pl 
Table 1. Published meta-analyses on the effects of probiotics

\begin{tabular}{|c|c|c|}
\hline Condition & References & Effect of probiotics \\
\hline Acute gastroenteritis (treatment) & {$[5-10]$} & $\begin{array}{l}\text { Approximately 1-day reduction in the duration of diarrhea; effect was strain } \\
\text { and dose dependent }\end{array}$ \\
\hline Antibiotic-associated diarrhea (AAD) & $\begin{array}{l}\text { Children only: }[11-13] \\
\text { Adults and children: } \\
\text { [14-17] }\end{array}$ & $\begin{array}{l}\text { Beneficial effect of selected probiotics in the prevention of AAD; the use of } \\
\text { probiotics with documented efficacy, in appropriate doses confirmed in } \\
\text { controlled trials, is probably acceptable whenever preventing this usually } \\
\text { self-limited complication is important }\end{array}$ \\
\hline Clostridium-difficile-associated diarrhea & {$[18-20]$} & Conflicting study results \\
\hline Traveler's diarrhea (TD) & {$[21,22]$} & Opposite study results \\
\hline Necrotizing enterocolitis & {$[23-25]$} & $\begin{array}{l}\text { Reduced the risk of severe necrotizing enterocolitis and mortality in preterm } \\
\text { infants who were born }<1,500 \mathrm{~g}\end{array}$ \\
\hline Helicobacter pylori infection & {$[26]$} & Improved eradication rates and reduced therapy-related side effects \\
\hline Functional gastrointestinal disorders & {$[27]$} & No evidence that lactobacillus supplementation is effective \\
\hline Irritable bowel syndrome & {$[28-32]$} & $\begin{array}{l}\text { In single-organism studies, lactobacilli do not appear to be effective; } \\
\text { bifidobacteria and certain combinations of probiotics demonstrate some efficacy }\end{array}$ \\
\hline Induction of remission in Crohn's disease & {$[33]$} & Insufficient evidence \\
\hline Maintenance of remission in Crohn's disease & {$[34]$} & $\begin{array}{l}\text { No evidence to suggest that probiotics are beneficial to the maintenance of } \\
\text { remission in Crohn's disease }\end{array}$ \\
\hline Induction of remission in ulcerative colitis & {$[35]$} & $\begin{array}{l}\text { Limited evidence suggests that probiotics added to standard therapy may } \\
\text { provide modest benefits }\end{array}$ \\
\hline Pouchitis & {$[36,37]$} & Reduced risk of pouchitis; the most promising agent was VSL\#3 \\
\hline Constipation & {$[38]$} & $\begin{array}{l}\text { Until more data are available, the use of probiotics should be considered } \\
\text { investigational }\end{array}$ \\
\hline Allergy prevention & {$[39,40]$} & Opposite study results \\
\hline Respiratory tract infections (RTIs) & {$[41]$} & $\begin{array}{l}\text { May have a beneficial effect on the severity and duration of symptoms of RTIs } \\
\text { but do not appear to reduce the incidence of RTIs }\end{array}$ \\
\hline
\end{tabular}

tistically significant effect and moderate clinical benefit of some probiotic strains in the treatment of acute watery diarrhea, mainly rotaviral, primarily in infants and young children. Given the available evidence, the European Society for Paediatric Gastroenterology, Hepatology and Nutrition and the European Society of Paediatric Infectious Diseases Expert Working Group [2] recently stated that selected probiotics with proven clinical efficacy (e.g. Lactobacillus GG, Saccharomyces boulardii) that are administered in appropriate dosages, according to the strain and the patient population, may be used as an adjunct to rehydration therapy for the management of acute gastroenteritis in children. Other probiotic strains may also be used provided their efficacy is documented in high-quality RCTs. Regarding the second indication, several systematic reviews, with or without a meta-analysis, have shown most of the tested probiotics to be effective in reducing the risk of AAD in the general (mainly adult) population and in children. For other disease states, although some preliminary results with probiotic use are promising, studies documenting clear effects are limited.

\section{Is a Meta-Analytical Approach Appropriate to Assess the Efficacy of Probiotics?}

Evaluation of the results of published meta-analyses reveals that, with few exceptions, probiotics administered for the treatment of a specific disease or condition are all evaluated together. The following question remains: is it appropriate to pool data on different probiotic microorganisms? It is tempting for the reviewers to produce a single estimate of the treatment effect. However, the results of a meta-analysis of all probiotics, regardless of the microorganisms used, may be misleading if appropriate consideration is not given to the interpretation of the pooled results.

\section{Arguments for Pooling Data}

The value of performing a meta-analysis is that by combining trials, the sample size is increased and, thus, the power. Pooling data on different probiotics allows one to (1) establish whether there is evidence of an effect; (2) determine the direction of the effect (3) determine the size of the effect (and the 95\% confidence interval around 
the effect); (4) assess the consistency of the effect across studies, and (5) identify the most promising probiotic(s). If many trials exist involving the administration of different probiotics to different participants with similar results consistently being seen in the various trials, the effect of the probiotic(s) has some generalizability. In addition, pooled data on different probiotics are important for demonstrating whether further research on these probiotics is substantiated. If so, these pooled data potentially may help identify the most promising microorganisms as well as the research questions to be addressed in future studies.

\section{Arguments against Pooling Data}

There are a number of arguments against pooling data. First, there is evidence that the beneficial effects of probiotics, particularly the immunomodulatory effects of individual probiotics observed in the host, differ greatly and are strain specific [3]. Second, probiotics vary by organism. In addition to the most commonly used lactic acid bacteria (e.g. lactobacilli, bifidobacteria), the yeast $S$. boulardii is often used. All of these probiotics have different properties and antipathogenic mechanisms. Consequently, their efficacy may vary. Third, the dose of probiotics may be important, as has been documented [4].

\section{What Could Be the Solution?}

Given these concerns, the best approach would be to perform a meta-analysis evaluating the effect of administering a clearly defined, single-organism, probiotic preparation or an equally well-defined combination of probiotic microorganisms for the treatment of a specific disease or condition. However, a lack of available data often makes this infeasible. With few exceptions, only seldom are there data from more than single studies on a given probiotic microorganism or combination of probiotic microorganisms. Another commonly used approach is to perform a review of all probiotics and then to perform subgroup analyses based on factors considered a priori that could potentially influence the magnitude of the treatment response. Examples of such factors are the following: (1) the type of probiotic administered; (2) whether the probiotic was live versus dead; (3) the medium, and (4) the study population (children, adults).

\section{Summary and Key Messages}

Systematic reviews, with or without a meta-analysis, are now a well-established means of reviewing existing evidence and integrating findings from various studies.

The best-documented areas of efficacy of probiotics are the treatment of acute infectious diarrhea and the prevention of $\mathrm{AAD}$.

Meta-analyses on probiotics provide valid information. However, caution should be exercised not to overinterpret the results of a meta-analysis when all probiotics have been evaluated together. Considering that the effects of probiotics are strain specific as well as population specific, they cannot be generalized.

\section{Disclosure Statement}

H.S. has received lecture and/or consultancy fees from Biocodex, France, Biomed Lublin, Biomed Krakow, Krotex Poland, Danone, Dumex, GlaxoSmithKline, Nestlé Nutrition Institute, Nestlé Poland, Nutricia Poland, Mead Johnson International, Mead Johnson Nutritionals Poland, and Merck.

\section{References}

1 Higgins JPT, Green S (eds): Cochrane Handbook for Systematic Reviews of Interventions Version 5.0.1 (updated September 2008). Cochrane Collaboration, 2008. www. cochrane-handbook.org.

-2 Guarino A, Albano F, Ashkenazi S, Gendrel D, Hoekstra JH, Shamir R, Szajewska H, European Society for Paediatric Gastroenterology, Hepatology, and Nutrition, European Society for Paediatric Infectious Diseases:
European Society for Paediatric Gastroenterology, Hepatology, and Nutrition/European Society for Paediatric Infectious Diseases evidence-based guidelines for the management of acute gastroenteritis in children in Europe. J Pediatr Gastroenterol Nutr 2008;46(suppl 2):S81-S122.

-3 O’Mahony L, McCarthy J, Kelly P, Hurley G, Luo F, Chen K, O'Sullivan GC, Kiely B, Collins JK, Shanahan F, Quigley EM: Lactobacil- lus and Bifidobacterium in irritable bowel syndrome: symptom responses and relationship to cytokine profiles. Gastroenterology 2005;128:541-551.

4 Whorwell PJ, Altringer L, Morel J, Bond Y, Charbonneau D, O'Mahony L, Kiely B, Shanahan F, Quigley EM: Efficacy of an encapsulated probiotic Bifidobacterium infantis 35624 in women with irritable bowel syndrome. Am J Gastroenterol 2006;101:1581-1590. 
5 Szajewska H, Mrukowicz J: Probiotics in the treatment and prevention of acute infectious diarrhea in infants and children: a systematic review of published randomized, double-blind, placebo-controlled trials. J Pediatr Gastroenterol Nutr 2001;33:S17-S25.

-6 Van Niel C, Feudtner C, Garrison MM, Christakis DA: Lactobacillus therapy for acute infectious diarrhea in children: a metaanalysis. Pediatrics 2002;109:678-684.

-7 Huang JS, Bousvaros A, Lee JW, Diaz A, Davidson EJ: Efficacy of probiotic use in acute diarrhea in children: a meta-analysis. Dig Dis Sci 2002;47:2625-2634.

8 Allen SJ, Okoko B, Martinez E, Gregorio GV, Dans LF: Probiotics for treating infectious diarrhoea. Cochrane Database Syst Rev 2003;4:CD003048.

-9 Szajewska H, Skórka A, Ruszczyński M, Gieruszczak-Białek D: Meta-analysis: Lactobacillus GG for treating acute diarrhoea in children. Aliment Pharmacol Ther 2007;25: 871-881.

10 Szajewska H, Skórka A: Saccharomyces boulardii for treating acute gastroenteritis in children, updated meta-analysis of randomized controlled trials. Aliment Pharmacol Ther 2009;30:955-963.

-11 Szajewska H, Ruszczynski M, Radzikowski A: Probiotics in the prevention of antibioticassociated diarrhea in children: a meta-analysis of randomized controlled trials. J Pediatr 2006; 149:367-372.

12 Johnston BC, Supina AL, Vohra S: Probiotics for pediatric antibiotic-associated diarrhea: a meta-analysis of randomized placebo-controlled trials. CMAJ 2006;175:377-383. Erratum in: CMAJ 2006;175:777.

13 Johnston BC, Supina AL, Ospina M, Vohra S: Probiotics for the prevention of pediatric antibiotic-associated diarrhea. Cochrane Database Syst Rev 2007;18:CD004827.

- 14 D'Souza AL, Rajkumar C, Cooke J, Bulpitt CJ: Probiotics in prevention of antibiotic-associated diarrhoea: meta-analysis. Br Med J 2002;324:1361-1364.

-15 Cremonini F, Di Caro S, Nista EC, Bartolozzo F, Capelli G, Gasbarrini G, Gasbarrini A: Meta-analysis: the effect of probiotic administration on antibiotic-associated diarrhoea. Aliment Pharmacol Ther 2002;16:14611467.

16 Szajewska H, Mrukowicz J: Meta-analysis: non-pathogenic yeast Saccharomyces boulardii in the prevention of antibiotic-associated diarrhea. Aliment Pharmacol Ther 2005;22: 365-372.
17 Hawrelak JA, Whitten DL, Myers SP: Is Lactobacillus rhamnosus GG effective in preventing the onset of antibiotic-associated diarrhoea: a systematic review. Digestion 2005; 72:51-56.

18 McFarland LV: Meta-analysis of probiotics for the prevention of antibiotic-associated diarrhea and the treatment of Clostridium difficile disease. Am J Gastroenterol 2006; 101:812-822.

19 Dendukuri N, Costa V, McGregor M, et al: Probiotic therapy for the prevention and treatment of Clostridium difficile-associated diarrhea: a systematic review. CMAJ 2005; 173:167-170.

20 Pillai A, Nelson R: Probiotics for treatment of Clostridium difficile-associated colitis in adults. Cochrane Database Syst Rev 2008;1:CD004611. DOI: 10.1002/14651858. CD004611.pub2.

21 McFarland LV: Meta-analysis of probiotics for the prevention of traveler's diarrhea. Travel Med Infect Dis 2007;5:97-105.

22 Takahashi O, Noguchi Y, Omata F, Tokuda Y, Fukui T: Probiotics in the prevention of traveler's diarrhea: meta-analysis. J Clin Gastroenterol 2007;41:336-337.

23 Deshpande G, Rao S, Patole S: Probiotics for prevention of necrotising enterocolitis in preterm neonates with very low birth weight: a systematic review of randomised controlled trials. Lancet 2007;369:1614-1620.

24 Alfaleh K, Bassler D: Probiotics for prevention of necrotizing enterocolitis in preterm infants. Cochrane Database Syst Rev 2008; 1:CD005496

25 Barclay AR, Stenson B, Simpson JH, Weaver LT, Wilson DC: Probiotics for necrotizing enterocolitis: a systematic review. J Pediatr Gastroenterol Nutr 2007;45:569-576.

26 Tong JL, Ran ZH, Shen J, et al: Meta-analysis: the effect of supplementation with probiotics on eradication rates and side effects during Helicobacter pylori eradication therapy. Aliment Pharmacol Ther 2007;25:155-168.

27 Huertas-Ceballos AA, Logan S, Bennett C, Macarthur C: Dietary interventions for recurrent abdominal pain (RAP) and irritable bowel syndrome (IBS) in childhood. Cochrane Database Syst Rev 2009;1:CD003019. DOI: 10.1002/14651858.CD003019.pub3.

28 McFarland LV, Dublin S: Meta-analysis of probiotics for the treatment of irritable bowel syndrome. World J Gastroenterol 2008;14: 2650-2661.

29 Nikfar S, Rahimi R, Rahimi F, Derakhshani S, Abdollahi M: Efficacy of probiotics in irritable bowel syndrome: a meta-analysis of randomized, controlled trials. Dis Colon Rectum 2008;51:1775-1780.
30 Hoveyda N, Heneghan C, Mahtani KR, Perera R, Roberts N, Glasziou P: A systematic review and meta-analysis: probiotics in the treatment of irritable bowel syndrome. BMC Gastroenterol 2009;9:15.

-31 Brenner DM, Moeller MJ, Chey WD, Schoenfeld PS: The utility of probiotics in the treatment of irritable bowel syndrome: a systematic review. Am J Gastroenterol 2009;104: 1033-1049.

32 Moayyedi P, Ford AC, Talley NJ, Cremonini F, Foxx-Orenstein A, Brandt L, Quigley E: The efficacy of probiotics in the therapy of irritable bowel syndrome: a systematic review. Gut 2008, Epub ahead of print.

33 Butterworth AD, Thomas AG, Akobeng AK: Probiotics for induction of remission in Crohn's disease. Cochrane Database Systematic Rev 2008;3:CD006634. DOI: 10.1002/ 14651858.CD006634.pub2.

34 Rolfe VE, Fortun PJ, Hawkey CJ, Bath-Hextall F: Probiotics for maintenance of remission in Crohn's disease. Cochrane Database Syst Rev 2006;4:CD004826. DOI: 10.1002/ 14651858.CD004826.pub2.

35 Mallon P, McKay D, Kirk S, Gardiner K: Probiotics for induction of remission in ulcerative colitis. Cochrane Database Syst Rev 2007;4: CD005573. DOI: 10.1002/14651858. CD005573.pub2.

36 Sandborn W, McLeod R, Jewell D: Pharmacotherapy for inducing and maintaining remission in pouchitis (review). Cochrane $\mathrm{Da}$ tabase Syst Rev 2000;2:CD001176.

- 37 Elahi B, Nikfar S, Derakhshani S, Vafaie M, Abdollahi M: On the benefit of probiotics in the management of pouchitis in patients who underwent ileal pouch anal anastomosis: a meta-analysis of controlled clinical trials. Dig Dis Sci 2008;53:1278-1284.

38 Chmielewska A, Szajewska H: Systematic review of randomised controlled trias: probiotics for functional constipation. World J Gastroenterol 2010;16:69-75.

39 Osborn DA, Sinn JK: Probiotics in infants for prevention of allergic disease and food hypersensitivity. Cochrane Database of Syst Rev 2007;4:CD006475.

40 Lee J, Seto D, Bielory L: Meta-analysis of clinical trials of probiotics for prevention and treatment of pediatric atopic dermatitis. J Allergy Clin Immunol 2008;121:116-121.

-41 Vouloumanou EK, Makris GC, Karageorgopoulos DE, Falagas ME: Probiotics for the prevention of respiratory tract infections: a systematic review. Int J Antimicrob Agents 2009;34:197.e1-e10. 